\title{
Comparative analysis of childhood depression and perceived social support among orphan girls and boys
}

\begin{abstract}
The study was conducted to measure the comparison and analyze childhood depression and perceived social support among orphan girls and boys. A sample of 300 students in which 150 girls and 150 were boys ranging between 10-15years of age were randomly selected from different orphanages of Rawalpindi, Haripur and Abbottabad. Childhood Depression Scale and perceived social support scale were administered. T-test, correlation and regression analysis were computed to investigate the variance and relationship as well. Results showed that there is significant difference in childhood depression and perceived social support and both are having meaningful relationship. Findings also revealed that perceived social support predict childhood depression among orphan boys and girls.
\end{abstract}

Volume 7 Issue 3 - 2017

\author{
Abdur Rashid, Sara Safdar \\ Foundation University Islamabad, Pakistan \\ Correspondence: Abdur Rashid, Foundation University \\ Islamabad, Pakistan, Email drrashidcac@yahoo.com
}

Received: January 14, 2017| Published: February 23, 2017

Keywords: childhood depression, perceived social support, orphans, orphanages

\section{Introduction}

A family is defined as " two or more people in a committed relationship from which they drive a sense of identity as a family". Thus a family can be seen as a most important group in which intimate relationship exists among its members and everything that happens to one member would have an effect on all the other members, specially the children. Hence it may be argued that the death of a closer family member especially the parental figure would have its devastating impact on children and family as a whole. Death of a loved one is one of the universal stressful life experiences; therefore it can lead to the temporary breakdown of symptoms of emotional disturbance for family. ${ }^{1}$

Significance of early parent child relationship in the course of socialization, parents serve important role as a teacher and model of their children. The presence of both mother and father strengthen the Childs initiative and confidence. Therefore loss of parents can disrupt normal functioning of the children as it involves critical changes in individual's social environment. Children loose not only a key relationship but also an important psychological support. They emphasized that when ones parent dies it often lead the surviving children to redefine the meaning of parenthood and the importance of time spent together. Thus it may be hypothesized that the absence of parents can cause depression in children and ultimately they develop poor self concept. ${ }^{2}$

\section{Childhood depression}

Depression is defined as a complaint when the feelings of depression continue and hinder with a child ability to function. ${ }^{3}$

Childhood depression is unlike the normal "blues" and everyday emotions that happen as a child develops. If a child is sad doesn't essentially mean he or she has depression. If the sadness becomes constant, or if troublemaking behavior interferes with normal social activities, interests, family life or school work it may indicate that he or she has a depression. ${ }^{4}$

Prevalence and predictors of depression among orphans in Dakahlia's orphanages, Egypt, revealed that $20 \%$ of orphans had depression and independent predictor of depression is child gender, Girls were about 46 times more likely to have depression than boys. ${ }^{5}$

A research investigated Psychosocial and Developmental Status of Orphanages children which concluded that there is high rate of emotional and developmental disorders among orphanages children where girls are more likely to develop depression, anxiety and developmental disorders. ${ }^{6}$

Study on risk and protective factors for depression symptoms among children affected by HIV/Aids in rural china revealed that traumatic events like death of parents and stigma related to HIV had a significant role in developing depression among orphan children. For protection of depression most important factor is trusting relationship. Further results discovered that trusting relationship, perceived social support and future orientation offers protection against traumatic events and HIV related stigma on depression. ${ }^{7}$

Protective factors for childhood depression includes involvement of supportive adults, strong family and peer relationships, healthy coping skills, and emotional regulation, safe and comfortable environment. $^{8}$

\section{Social Support}

Social support is a process of communication in relationship which improves self-esteem, coping, belonging and capability through actual or perceived interactions of physical or psychological resources. ${ }^{9}$

Depression is so destructive; research has focused on identifying risk factors for this disorder. A leading viewpoint is that deficits in social support increase the risk for depression. ${ }^{10}$

Theoretically, the perception that one is accepted and valued in one's interpersonal environment boosts esteem, confidence, and efficacy, which play role of protector against depression.

The stress-buffering model asserts that social support mitigates the relation between stressful life events and depression. Deficits in perceived support have predicted future increases in depressive symptoms during adolescence. ${ }^{11}$ 
Study on the role of perceived social support in loneliness and selfesteem among children affected by Hiv/Aids in rural china indicated that children with higher perceived social support reported lower loneliness score and children with higher perceived social support reported high level of self-esteem and low level of depression. ${ }^{12}$

\section{Methods}

\section{Objectives}

To achieve the aims of research certain objectives were accomplished, these objectives are as following:

a. To study the relationship of perceived social support and childhood depression among orphan boys and girls.

b. To determine the impact of perceived social support and childhood depression among orphan boys and girls.

\section{Hypotheses}

In the light of literature review following hypotheses have been formulated:

1. There will be a significant difference among childhood depression and perceived social support among orphan boys and girls.

2. Childhood depression and perceived social support will have a significant relationship.

3. Perceived social support will predict childhood depression among orphan boys and girls.

\section{Sample}

Sample consists of $(\mathrm{N}=300)$ (boys $=150)$ and (girls $=150)$. Sample was taken from SOS villages and Faiz-ul-islam school of Rawalpindi,
Participants were also selected from orphanages of Haripur and Abbottabad by using purposive sampling technique. Age range of sample was 10 to 15 years.

\section{Assessment measures}

The following measures were used to assess the construct of the study:

Childhood depression: Childhood Depression Scale" developed by Musarrat Jabeeen Khan (2005) is used in study. Cut off Score of scale is 128 . Children who score more than 128 are at the high risk of depression.

Perceived social support: Perceived social support scale" developed by (Rifai 2002) is used in this study. It measures social support in four domains i-e family, friends, relatives and work environment. High scores show high level of social support whereas low score shows lack of social support.

\section{Procedure}

Permission letter of institutional support to visit orphanages was taken from Head of department. Concerned authorities of institutions were contacted through telephone, with their permission days were selected for visit. They were assured about confidentiality of the data. Two standardized scales childhood depression scale and perceived social support scale were used for data collection. Participants were cordially thanked for the provision of valuable information and data.

\section{Results}

(Table 1) Results showed that girls have more childhood depression and there is difference in family support, friends, relatives and work environment support among orphan boys and girls (Table 2).

Table I Differences in childhood depression and perceived social support along with subscales among orphan boys and girls

\begin{tabular}{lllllllll}
\hline & Boys & & Girls & & P & T & 95\%Cl \\
\hline Variables & M & SD & M & SD & & & Cohens (d) \\
CD & 90.76 & 14.88 & 128.69 & 24.5 & 0 & -16.15 & $-42.54,-33.30$ & -1.87 \\
FAM & 24.94 & 3.52 & 23.18 & 4.19 & 0 & 3.93 & $.87,2.64$ & 0.45 \\
FRI & 15.32 & 3.2 & 16.24 & 2.9 & 0 & -2.6 & $-1.61,-.22$ & -0.3 \\
REL & 11.34 & 2.5 & $10.5 \mathrm{I}$ & 4.17 & 0.03 & 2.08 & $.04,1.61$ \\
W.E & 10.88 & 0.2 & 0 & 0.16 & 0 & 3.36 & $.36,1.39$ & 0.24 \\
\hline
\end{tabular}

Note: Boys (N= I50); Girls (N=I50); CD: Childhood Depression; Fam: Family; Fri: Fiends; Rel:

Relatives;WE:Work Environment.

Results showed that girls have more childhood depression and there is difference in family support, friends, relatives and work environment support among orphan boys and girls.

Table 2 Correlation between childhood depression and perceived social support along with subscales among orphan girls ( $\mathrm{N}=\mathrm{I50})$

\begin{tabular}{|c|c|c|c|c|c|}
\hline Variables & I & 2 & 3 & 4 & 5 \\
\hline$C D$ & & -0.143 & -0.015 & 0.147 & $-.231 * *$ \\
\hline FAM & & & 0.094 & $.181 *$ & $.369 * *$ \\
\hline FRI & & & & $.202 *$ & $.250 * *$ \\
\hline REL & & & & & 0.11 \\
\hline W.E & & & & & - \\
\hline
\end{tabular}

Note: $* \mathrm{P}<.05 ; * * \mathrm{P}<.0 \mathrm{I}$; CD: Childhood Depression; Fam: Family; Fri: Fiends; Rel: Relatives;WE:Work Environment.

Results revealed that childhood depression has significant negative relationship with work environment support. It has negative but nonsignificant relationship with family and friends support. Relatives support has positive non significant relationship with childhood depression. Significant negative relationship indicates that girls with high childhood depression are likely to have less work environment support. Family support has significant positive relationship with relatives and work environment support. It has positive non-significant relationship with friends support. Positive relationship indicated that girls with high family support are likely to have more relatives and work environment support. Friends support has significant positive relationship with relatives and work environment support. This 
relationship indicated that girls with high friends support are likely to have more relatives and work environment support. Relatives support has non-significant positive relationship with work environment (Table 3).

Table 3 Correlation between childhood depression and perceived socia support along with subscales among orphan boys $(\mathrm{N}=150)$

\begin{tabular}{|c|c|c|c|c|c|}
\hline Variables & I & 2 & 3 & 4 & 5 \\
\hline CD & & -0.191 & -0.118 & -0.052 & $-.27 * *$ \\
\hline FAM & & & 0.085 & $.311 * *$ & $.346 * *$ \\
\hline FRI & & & & 0.083 & $.179 *$ \\
\hline REL & & & & & $.374 * *$ \\
\hline W.E & & & & & - \\
\hline
\end{tabular}

Note: $* \mathrm{P}<.05 ; * * \mathrm{P}<.0 \mathrm{I} ; \mathrm{CD}:$ Childhood Depression; Fam: Family; Fri: Fiends; Rel: Relatives;WE:Work Environment.

Results revealed that childhood depression has significant negative relationship with work environment. It has negative relationship with family, friends and relatives support while this relationship is nonsignificant. This negative relationship suggests that Boys with high childhood depression are likely to have less work environment support. Family support has significant positive relationship with relatives and work environment support. It has positive relationship with friends support while this relation is non-significant. Significant positive relationship suggested that Orphan boys with more family support are likely to have more relatives and work environment support. Results indicated that friends support has significant positive relationship with work environment support. It has positive but non-significant relationship with relatives support. Significant positive relationship between friends support and work environment suggested that boys with more friends support are likely to have more work environment support (Table 4)

Table 4 Summary of Hierarchical regression analysis of perceived socia support along with subscales predicting childhood depression among orphan girls $(\mathrm{N}=150)$

\begin{tabular}{llll}
\hline Predictors & B & SE & $\boldsymbol{\beta}$ \\
\hline Fam & 0.18 & 0.42 & 0.03 \\
Fri & -0.96 & 0.62 & -0.11 \\
Rel & $.70 *$ & 0.39 & 0.11 \\
WE & $-1.1 \mathrm{I}$ & 0.87 & -0.92 \\
R & 0.66 & & \\
R2 & $.44 * *$ & & \\
$\Delta R$ & $.40 * *$ & & \\
F & 13.75 & & \\
\hline
\end{tabular}

Note: *P<.05; **P<.0I; CD: Childhood Depression; Fam: Family; Fri: Fiends; Rel: Relatives;WE:Work Environment

Results indicated that relatives support emerged as significant predictors of childhood depression among orphan girls (Table 5).

Table 5 Summary of Hierarchical regression analysis of perceived socia support along with subscales predicting childhood depression among orphan boys $(\mathrm{N}=150)$

\begin{tabular}{llll}
\hline Predictors & B & SE & $\boldsymbol{\beta}$ \\
\hline Fam & $-0.1 \mathrm{I}$ & 0.33 & -0.02 \\
Fri & 0.29 & 0.34 & 0.06 \\
Rel & 0.82 & 0.47 & 0.13 \\
WE & $-1.1 \mathrm{I} *$ & 0.49 & -0.18 \\
R & 0.54 & & \\
R2 & $.30 * *$ & & \\
$\Delta$ R & $.26 * *$ & & \\
F & 7.62 & & \\
\hline
\end{tabular}

Note: $* \mathrm{P}<.05$;**P<.0 I; CD: Childhood depression; Fam: Family; Fri: Fiends; Rel:

Relatives;WE:Work Environment.
Results revealed that Relatives and work environment support emerged as significant predictor of childhood depression among orphan boys.

\section{Discussion}

First finding of study revealed that there is significant difference in social support (family support, friends, relatives and work environment support) among orphan boys and girls. This finding was supported by Gilany et al., ${ }^{13}$ according to them orphan boys are more socialized than girls. Many cultures enhances male independence while females may feel insecure this can contribute to the feeling of social rejection among females. Present study reported that girls express greater feelings of abuse and mistrust than boys. Social isolation is more common among girls; the rules of our culture prevent girls from becoming more sociable. Behrendt $\&$ Mor $^{14}$ reported that for girls, care and affection in the family, receiving gifts, and satisfying their basic needs were the most important sources of happiness, whereas for boys the company of peers was the source of happiness.

Further results revealed that childhood depression has significant negative relationship with work environment support. Family support has significant positive relationship with relatives and work environment support. Positive relationship indicated that girls with high family support are likely to have more relatives and work environment support. Friends support has significant positive relationship with relatives and work environment support. Childhood depression has no relationship with family and friends support. This relationship indicated that girls with high friends support are likely to have more relatives and work environment support. Eather \& Morgan ${ }^{15}$ found that emotional support from either a class teacher or a life skills teacher or a school counselor had significant role in psychological well being of students and lack of work environment support can make children vulnerable to depression. By providing support to depressed children symptoms of depression decrease over time. He also found that children relay on the social support of their family and friends and their support plays vital role in psychological well being especially in depression, this finding is contrary to present research which stated that there is no relation between depression and support of family and friends. This difference can be because of cultural differences. Mostly orphans in present study were institutionalized and were not living with family.

Third Hypothesis of research stated that perceived social support along with subscales is likely to predict childhood depression among orphan boys and girls. Results indicated that social support (relatives support, work environment support) emerged as significant predictors of childhood depression for orphan boys and relatives support emerged as significant predictor of childhood depression among orphan girls. These findings are empirically supported by research ${ }^{10}$ the stressbuffering model asserts that social support mitigates the relation between stressful life events and depression. Deficits in perceived support have predicted future increases in depressive symptoms during adolescence.

\section{Limitations}

The first limitation of the study is that only 5 to 10 grade students were focused however any orphan below and above this age range can also suffer from depression and problems of social support. Another major limitation of this study is that data was collected from limited cities of only two provinces Punjab and Khyber Pakhtunkhawa and the other provinces were ignored, because of cultural differences, there may be different findings from other provinces. The total sample was 300 orphans that are too short to generalize the results throughout 
the population. Data was collected from orphans living in orphanages, those orphans living with surviving parent or relatives were not taken in study.

For instance present study was based on comparative research design which only tells that there is a relationship but does not tells that why this relationship occurs. However, employing other quantitative research designs e.g., cross sectional research design along with qualitative measures i.e., in-depth interview and focus group would permit the respondents greater liberty to share their problems, interest and views about their feeling and perceptions which would ultimately produce broader and detailed picture of phenomena.

\section{Suggestions}

This research work has a scope for future research and this can be expanded to explore certain other issues which are in relation but have not been covered in this research work. The sample used in this research was only institutionalized orphans while the same research can be done on orphans living with surviving parent, guardian, relatives or adopted families. This can benefit in a way that the sample of the people from different age groups can be studied and then a comparison can be made. Moreover, the orphans from different geographic areas can be selected and then their results can be compared. This will help to examine the depression and social support problems of orphans in different parts of the country in relation to the possible reasons behind them. This will enhance the knowledge in this particular area of research.

Socio economic factor of orphans living with single parent can be taken into account to study their mental well being. Academic institution should provide psychological consultation and proper psychotherapeutic measures for those students who are suffering from childhood depression and social support problems so that they can cope with it effectively. Teachers training programs should also need to be conducted so that they can identify such cases at initial stage which will further help the students to seek treatment at proper time. Analysis were only done with reference to orphan boys and girls whereas further studies in this dimension should carry out analysis on age, education, geographical affiliation i.e., urban rural, family type, specific behavior, social or physical health problems among orphan and non-orphan adolescents.

\section{Acknowledgments}

None.

\section{Conflicts of interest}

Author declares there are no conflicts of interest.

\section{Funding}

None.

\section{References}

1. Amato PR. Family and its importance in life of children. Journal of Marriage and Family. 1988;62:1269-1287.

2. Warren SL, Huston L, Egeland B, et al. Child and adolescent anxiety disorders and early attachment. $J$ Am Acad Child Adolesc Psychiatry. 1997;36(5):637-644.

3. American Academy of Child and Adolescent Psychiatry. Childhood depression and use of medication in treating childhood and adolescent depression. 2013.

4. Renee A, Alli MD. National Institute of Mental Health: Depression in Children and Adolescents. 2014.

5. Ibrahim A, Mona A, Khater M. Prevalence and predictors of depression among orphans in Dakahlia's orphanages, Egypt. International Journal of Collaborative Research on Internal Medicine \& Public Health. 2001.

6. Fawzy N, Fouad A. Psychological and developmental status of orphanage children. Current Psychiatry. 2010;17(2):41-48.

7. Wang B1, Li X, Barnett D, et al. Risk and protective factors for depression symptoms among children affected by HIV/ Aids in rural china. Soc Sci Med . 2012;74(9):1435-1443.

8. Gladstone T, Beardslee WR. The prevention of adolescent depression. Psychiatric Clinics. 2011;34(1):35-52.

9. Gotlib IH, Cohen C. Social support and its importance. The Scientific World Journal. 2000;16(2):41-48.

10. Windle M. A longitudinal study of stress buffering for adolescent problem behaviors. Developmental Psychology. 1992;28(3):522-530.

11. Lewinsohn PM, Hops H, Roberts RE, et al. Adolescent psychopathology. J Abnormal Psychol. 1993;102(4):517.

12. Qiao S, Li X, Zhao G, et al. Role of perceived social support in loneliness and self-esteem among children affected by HIV/AIDS. AIDS. 2014;28(Suppl 3):s369-s377.

13. Gilany AH, Blisha MA, Ibrahim A. Gender differences in maladaptive cognitive schemas in orphans in Dakahlia Egypt. Scientific World Journal. 2011;24:373120.

14. Alice Behrendt, Serigne MM. The psychological impact of parental loss and orphan-hood of children in an area of high HIV prevalence: A cross sectional study in North West region of Cameroon. 2008.

15. Eather N, Morgan PJ, Lubans DR. Social support from teachers mediates physical activity behavior change in children. Int J Behav Nutr Phys Act . 2013;10:68. 